\section{LASER SHOCK PEENING OF} ALUMINIUM ALLOYS TO ENHANCE SURFACE
PROPERTIES

JAN KAUFMAN, MAREK BOHM, JAN BRAJER, SANIN ZULIC

HiLASE, Institute of Physics of the ASCR, v.v.i., Czech Republic,

DOI : 10.17973/MMSJ.2019_12_2019114

jan.kaufman@hilase.cz

Laser Shock Peening (LSP) is a process where high energy nanosecond laser pulses are used to modify surface characteristics of treated materials. In this work, the LSP process is briefly explained and its effects on roughness, hardness and residual stresses of aluminium alloy 5083 are demonstrated. The LSP process is based on small plastic deformation caused by laser impacts on the surface which naturally increases roughness. It has been shown that the increase in roughness can be partially mitigated by strategic overlapping of individual laser pulses. The hardness of the peened surface has been increased by $19 \%$ and uniform compressive residual stresses up to $200 \mathrm{MPa}$ have been created over a large area. The compressive stresses reached about 1.2 $\mathrm{mm}$ deep inside the samples.

KEYWORDS

Laser Shock Peening, residual stress, cold working, surface processing, AA5083

\section{INTRODUCTION}

The technology of Laser Shock Peening (LSP) can be characterized as a surface engineering process that utilizes mechanical shock waves to induce structural changes inside treated materials. The shock waves are generated during the interaction of material with nanosecond high energy laser pulses. The origin of the method can be traced back to the beginning of 1970s [Anderholm 1970] although the first real application arrived 20 years later where it was used to solve the problem of B1 bomber and F101 fighter jet engine blades breaking off as a consequence of Foreign Object Damage (FOD) [Clauer 1991]. Since then, LSP technology has been applied to a number of industrial problems such as Stress Corrosion Cracking (SCC) of nuclear reactor vessels in Japanese nuclear power plants [Sano 2006] or laser forming of Boeing 747-8 wing sections [Rankin 2013]. For a long time, the main obstacle towards reaching smaller scale applications was lack of suitable and sufficiently cheap laser sources. However, a rapid development of new cheaper laser sources in the past couple of years helped LSP to find new applications in many research and industrial fields.

Regarding conventional processes, LSP can be best compared to Shot Peening (SP) [Gujba 2014] during which a material surface is bombarded by high velocity projectiles such as metallic or glass balls of various sizes. Similar to LSP, the main effect is also the creation of compressive residual stresses but the depth where theses stresses reach is much lower. Typically around 250 um when compared to depths over $1 \mathrm{~mm}$ with LSP (depends on sample thickness). Another advantage LSP has over SP is precise control of each laser impact location whereas peening of larger areas during SP is achieved through statistical overlap of random shot impacts. The overall roughness of peened surface is thus better in LSP while the surface after SP usually required some additional finish such as mechanical polishing which can however negatively modify the surface residual stresses. This is especially impactful in applications where surface roughness plays a significant role.

LSP technology can be applied to large number of materials such as various aluminium alloys [Hfaiedh 2015], numerous steel [Yoshihiro 2012] and copper [Ye 2014] alloys, zinc [Thareja 2007], nickel [Bugayeva 2006] and magnesium [Zhang 2010] alloys, amorphous metals [Fu 2014] etc. In this paper, the effect of LSP on marine grade aluminium alloys 5083 is investigated.

\section{LASER SHOCK PEENING}

Before the treatment, the sample is usually covered with a protective overlay such as black vinyl tape or paint. This layer protects the underlying sample from heat affects generated during the laser pulse absorption. Any effect on the material is then of mechanical nature which makes LSP a cold-working process. On top of the protective layer is a confinement layer 2$3 \mathrm{~mm}$ thick, usually created by laminar flow of water. The function of the water layer is to temporarily confine the plasma expansion against the material surface which leads to longer lasting (tens of ns) higher magnitude pressure (up to $5 \mathrm{GPa}$ ) when compared to peening without confinement [Fabbro 1990]. Thanks to the confinement phenomena, no vacuum [Anderholm 1970] is needed in order to achieve sufficient pressures which is key to viable industrial applications. Before reaching the sample, the laser pulse is focused by a lens, passes through the thin water layer and ablates a small part of the protective layer (Fig. 1(a)). A rapidly expanding plasma plume is created which absorbs the rest of the laser pulse energy. The typical power density is $1-10 \mathrm{GW} / \mathrm{cm}^{2}$. During the plasma expansion, a shock wave is generated which propagates inside the underlying material (Fig. 1(b). If the pressure exceeds the elastic limit of the material, a small plastic deformation occurs in the impact location. As the material tends to move away, it is confined by the surrounding material which results into creation of compressive residual stresses. In order to treat larger areas $\left(\sim \mathrm{cm}^{2}\right)$, the laser impacts are precisely placed next to each other in an overlapping pattern. The pattern strategy has a direct effect on the residual stress distribution [Hfaiedh 2015].
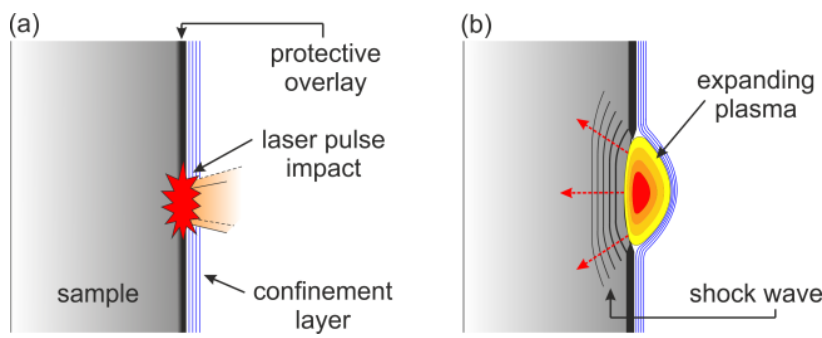

Figure 1. Simplified scheme of the LSP process. (a) Laser pulse passes through the confinement layer, ablates the protective overlay and plasma is created. (b) The expanding plasma is confined against the sample and strong shock waves are generated, inducing plastic deformation of the surface.

\section{MATERIAL}

Aluminium-magnesium alloy AW 5083-H116 is a low cost, high strength-to weight ratio, weldable material with an excellent uniform corrosion resistance properties. The temper H116 stands for special strain hardening, commonly used for magnesium rich aluminium alloys. It has been used as a light weight substitute for steel in the marine industry since World War 2. Chemical composition is shown in Tab. 1. 


\begin{tabular}{|c|l|l|l|l|l|r|}
\hline Alloy & Mg & Si & Mn & Fe & Cr & Other \\
\hline 5083 & $4.0-4.9$ & 0.4 & $0.4-1.0$ & 0.4 & 0.1 & 0.6 \\
\hline
\end{tabular}

Table 1. Chemical composition (wt\%) of aluminium alloy 5083.

It has been observed that alloys containing more than $3 \%$ of $\mathrm{Mg}$ become sensitized and susceptible to localized corrosion, particularly intergranular corrosion (IGC), when exposed to standard service temperatures for extended periods of time. These elevated temperatures can be as low as $50^{\circ} \mathrm{C}$, a common occurrence at sea, especially in tropical environments. IGC can then lead to mass loss through grain fall-out (exfoliation) which can result in intergranular stress corrosion cracking (SCC) as well as corrosion fatigue in presence of tensile stresses as a consequence. Between 2001 and 2002, for example, over 200 commercial ships made of AA5083 were found to be susceptible to IGC and needed to have their hulls and other structures completely replaced [Holroyd 2016].

In order for SCC to develop, three factors need to be present at the same time: susceptible material, corrosive environment and tensile stresses. When one of the factors is missing, SCC will not develop. Out of these three factors, the tensile stresses were targeted in this work.

\section{EXPERIMENTAL}

\subsection{Processing parameters}

The aluminium plate with $6 \mathrm{~mm}$ thickness was sectioned into coupons $4 \mathrm{~cm} \times 4 \mathrm{~cm}$. Prior to peening, each coupon was progressively ground to 1200 grit. The LSP was performed using a Q-switched Yb:YAG laser (Bivoj) that operates on wavelength of $1030 \mathrm{~nm}$. The pulse energy was $1.3 \mathrm{~J}$ with a width of $14 \mathrm{~ns}$. The spot size was $2 \mathrm{~mm}$ which gives the power density of 2.2 $\mathrm{GW} / \mathrm{cm}^{2}$. The beam profile was a top hat square. The repetition rate was $10 \mathrm{~Hz}$. During the peening the coupons were mounted on a 6-axis robotic arm which moved the coupon in a $X Y$ pattern (laser was coming horizontally from the side). The movement was synchronized with the laser operation. The coupons were covered with a black vinyl tape and a steady stream of laminar water flow was present on top. A pattern (layer) of overlapping (50\%) pulse impacts was created. In order to prevent tearing of the vinyl tape, each layer was subdivided into 4 sequences, each with $0 \%$ overlap, which would be placed on top of one another to create the $50 \%$ overlap. The sequencing is shown in Fig. 2. In total, 2 layers were applied with slight $X Y$ offset to smoothen out the deformed surface. The coupon surface after the peening is shown in Fig. 3.

1

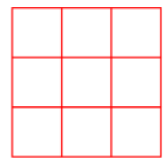

2

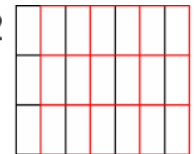

3
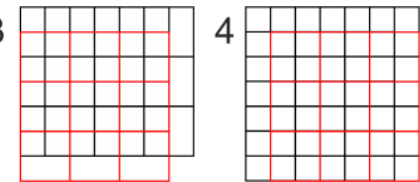

Figure 2. 1 LSP layer consisting of 4 sequences to create $50 \%$ overlap. New vinyl tape is applied after each sequence.

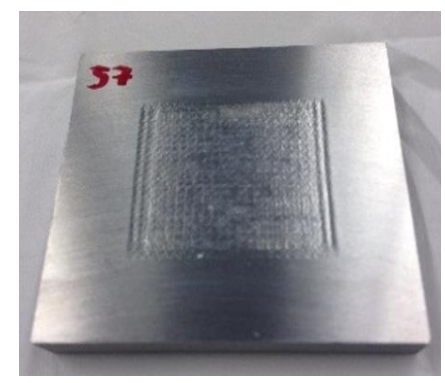

Figure 3. Test sample after peening.

\subsection{Residual stress, hardness and roughness measurements}

The stress measurements were done with an X-ray diffractometer (XRD) Proto LXRD instrument using the $\sin ^{2} \psi$ method. In this method, several Bragg peak measurements are taken at different tilts psi $(\psi)$ where $\psi$ is the angle between the normal of the sample and normal of the diffracting plane. The Bragg peak position is linked with the inter-planar spacing (d) and when anisotropic strain is present, $d$ becomes angle dependent which causes the shift of the Bragg peaks measured at different $\psi$. The stress is then calculated by fitting the peak position data in $d$ versus $\sin ^{2} \Psi$ plot using $X$-ray diffraction elastic constants of the material. The measurement parameters are listed in Tab. 2.

\begin{tabular}{|c|c|}
\hline Item & Description \\
\hline Radiation & $\mathrm{Cr} \mathrm{Ka}_{1}(\lambda=2.2897$ Angstrom $)$ \\
\hline Tilt angles & $0, \pm 2.58, \pm 9.07, \pm 12,45, \pm 18.8, \pm 23.0$ \\
\hline Aperture size & $2 \mathrm{~mm}$ \\
\hline Bragg's angle & $139^{\circ}$ \\
\hline Young modulus & $70.3 \mathrm{GPa}$ \\
\hline Poisson ration & 0.33 \\
\hline
\end{tabular}

Table 2. XRD parameters for residual stress measurements

To measure residual stress through depth, layers of the material were progressively removed using electropolisher with 87.5:12.5 vol\% $\mathrm{CH}_{3} \mathrm{OH}: \mathrm{H}_{2} \mathrm{SO}_{4}$ electrolytic solution. The thickness of material removed was measured with a precise micrometer. Smaller steps were taken close to the material surface. Strain and depth corrections were applied using the evaluation software.

The hardness measurements were obtained using a CSM Instruments Nano-Micro Indentation system with a Berkovich indenter, a load of $100 \mathrm{mN}$ with loading/unloading rate of 200 $\mathrm{mN} / \mathrm{min}$. The coupon was cross sectioned and polished and 3 hardness values were recorded at each depth.

For the surface mapping, WYKO NT1100 Optical Profiling system was used. The measurement is contactless, based on optical phase-shifting and white light vertical scanning interferometry.

\section{RESULTS}

\subsection{Surface roughness}

A key component of the Laser Shock Peening process is small plastic deformation of the laser pulse impact location. The plastic deformation creates strain in the material which results into the compressive residual stresses. Depending on peening parameters and protective overlay material, the dimple depth in case of aluminium can reach up to $40 \mathrm{um}$. In this case, the 
depth was about 25 um. A single laser shot impact deformation is shown in Fig. 4(a). The dimple profile closely follows the square top hat beam profile of the laser. Placing many of these dimples next to each in a periodic pattern necessarily leads to increased surface roughness. Fig. 4(b) shows the surface profile when 2 identical layers of LSP are applied. Fig. 4(c) then shows

(a)
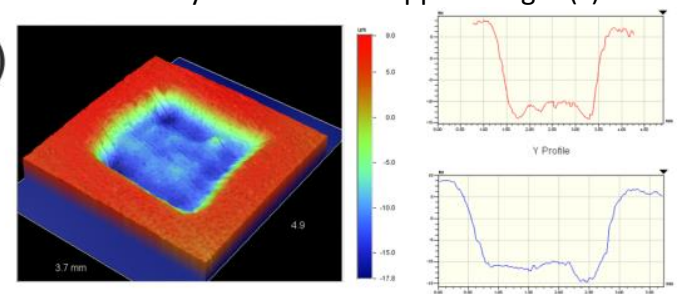

(b)

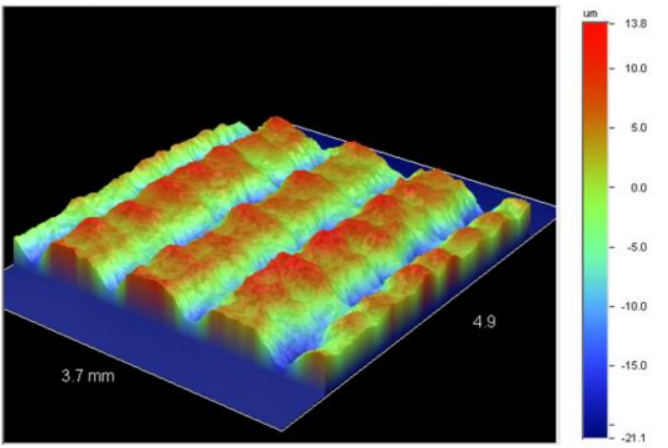

(c)

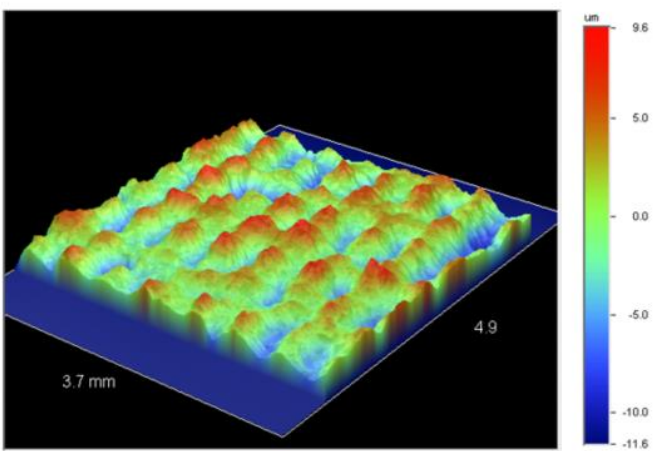

Figure 4. Sample surface after laser peening. (a) single laser shot impact, (b) surface peened with 2 overlapping layers and (c) surface peened with 2 layers mutually offset by one quarter of laser spot size in both directions.

the surface when the 2 layers are applied with an offset equal to a quarter of the spot laser spot size in both $X$ and $Y$ direction. The surface roughness for each condition is summarized in Tab. 3. While not restoring the initial smooth surface, the offset layers decrease the roughness created by non-offset layers to about half its value.

\begin{tabular}{|c|c|}
\hline Condition & Surface roughness Ra [um] \\
\hline no LSP & 0.23 \\
\hline LSP 2 layers & 5.64 \\
\hline LSP 2 layers offset & 2.59 \\
\hline
\end{tabular}

Table 3. Surface roughness before and after LSP.

\subsection{Residual stress}

In general, the residual stresses generated by LSP are dependent on the peening direction. The measurements were therefore obtained in two orthogonal directions. The scanning direction is denoted by $\mathrm{S}$ (direction of the peening lines) and the transversal direction is denoted by $T$ (across the peening lines). Depending on the peening strategy, the stresses generated in these two directions can vary substantially. In this case, both surface and in-depth residual stresses were measured.
The surface stresses were measured in a line stretching across the peened patch. Nine points were measured in total with a $3.3 \mathrm{~mm}$ step between each point. The step value was selected so that the points would avoid any possible periodicity of the peened pattern. The results are shown in Fig. 5.

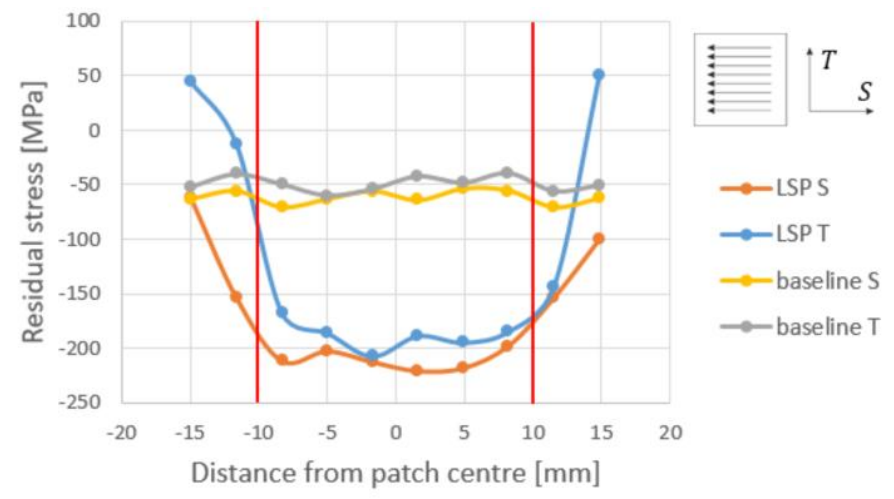

Figure 5. Surface residual stresses measured across the peened patch. The edges of the patch are marked by red lines.

The compressive stresses were increased in both directions with maximum values of $-221 \mathrm{MPa}$ and $-207 \mathrm{MPa}$ in S and $\mathrm{T}$ direction, respectively. Over the patch area, the stresses are compressive and relatively uniform with a sharp drop off outside the patch. In T direction, the stresses turn tensile at the edges of the measurement area. That is to be expected since without any external forces, the sample is in a state of stress equilibrium which means that the total sum of residual stresses in the sample is zero. The laser peening merely causes a redistribution of the stresses. This is especially useful as the compressive stresses can be created in a critical component area which is for example prone to fatigue failure.

The depth residual stresses are shown in Fig. 6 . In this case, the maximum stress values achieved were -194 $\mathrm{MPa}$ and $-223 \mathrm{MPa}$ in $\mathrm{S}$ and $\mathrm{T}$ direction, respectively. Similarly, the compressive stresses reached over $1.2 \mathrm{~mm}$ in $\mathrm{S}$ and around $1.1 \mathrm{~mm}$ in $\mathrm{T}$ (the sample was $6 \mathrm{~mm}$ thick). The LSP process thus introduced deep residual stresses into a previously relaxed sample. The results are summarized in Tab. 4.

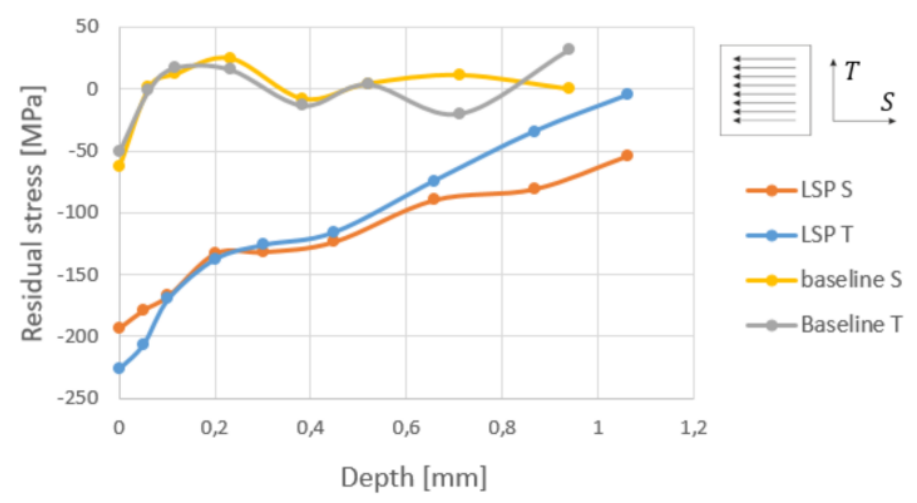

Figure 6. Depth residual stress. Different depth levels were obtained by electropolishing the sample. The data was strain and depth corrected.

\begin{tabular}{|c|c|c|}
\hline Condition & $\begin{array}{c}\text { Max compressive } \\
\text { stress [MPa] }\end{array}$ & $\begin{array}{c}\text { Compression } \\
\text { depth [mm] }\end{array}$ \\
\hline LSP S & -194 & 1.2 \\
\hline LSP T & -223 & 1.1 \\
\hline baseline S & -63 & 0.06 \\
\hline baseline T & -50 & 0.06 \\
\hline
\end{tabular}

Table 4. Maximum compressive residual stresses and compression depth. 


\subsection{Hardness and XRD peak broadening}

The XRD peak broadening is a qualitative indicator of plastic strain introduced in a material. The broadening is characterized at full width half maximum value of the peak (FWHM). It was measured simultaneously with residual stress depth profile data and was plotted in Fig. 7. The graph shows that the level of plastic strain is the highest at the surface (FWHM 1.91) and then drops off to a constant value of 1.68 at a depth of about 400 um.

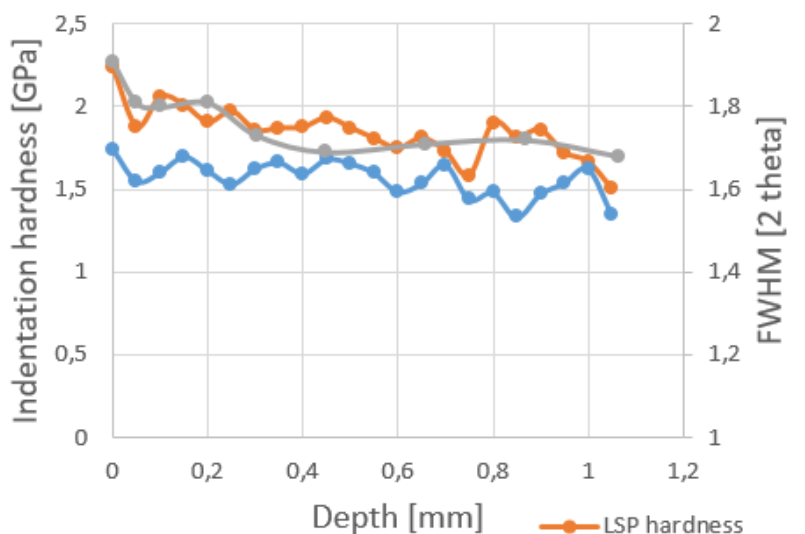

—baseline hardness

$\longrightarrow$ peak broadening

Figure 7. Indentation hardness and FWHM of diffraction peak through depth in LSP treated aluminium alloy 5083.

After LSP, the indentation hardness at the surface was about $2.2 \mathrm{GPa}$ and dropped gradually to the baseline level of $1.6 \mathrm{GPa}$ at a depth of about $700 \mathrm{um}$. The surface hardness of the unpeened sample was 1.7 which means a $19 \%$ increase in surface hardness after LSP.

\section{CONCLUSIONS}

The subject of this work was to study the influence of the Laser Shock Peening process on surface material characteristics of aluminium alloy 5083. It has been found that despite the increases in surface roughness due to the inherent plastic deformation that occurs during the laser peening process, the impact can be lessened by strategic pattern overlapping where consecutive LSP layers are used to smoothen out the periodic deformations caused by previous layers.

Uniform compressive residual stresses were measured across the peened patch with a sharp drop off and even change to tensile stresses outside the peened patch. This result shows that the LSP treatment should be applied with a consideration as not to induce unwanted tensile stresses outside the treated area where these could be harmful. The compressive stresses induced reached over $1 \mathrm{~mm}$ in depth. The highest compression was at the surface with a steady decrease with depth. The deep compressive stresses often lead to bending of the treated material, especially when the treated part is thin. This can be counteracted by peening from both sides of the sample simultaneously.

An increase in hardness and strength was observed with highest values at the surface and steady levelling off deeper inside the material. Simultaneously an XRD peak broadening was measured implying higher plastic strain induced by the LSP process.
The following research will be focused on how these material changes directly impact the stress corrosion cracking behaviour of the aluminium alloy 5083 .

\section{Acknowledgments}

This work was supported by European Structural and Investing Funds, Operational Programme Research, Development and Education (Grant agreement NO CZ.02.1.01/0.0/0.0/15_006/ 0000674) and from the European Union's Horizon 2020 research and innovation programme (Grant agreement NO 739573), and by the Ministry of Education, Youth and Sports of the Czech Republic (Programmes NPU I-Project no. LO1602 and Large Research Infrastructure Project No. LM2015086).

\section{REFERENCES}

[Anderholm 1970] Anderholm, N.C. Laser generated stress waves. Applied Physics Letters, 1970, Vol.16, No.3, 10.1063/1.1653116

[Clauer 1991] Clauer, A., Koucky, J., et al. Laser Shock Processing Increases the Fatigue Life of Metal Parts. Materials and Processing Report, 1991, Vol.6, No.6, 10.1080/08871949.1991.11752452

[Sano 2006] Sano, Y., Akita, K., et al. Laser Peening without Coating as a Surface Enhancement Technology. Journal of Laser Micro/Nanoengineering, 2006, Vol.1, No.3, 10.2961/jlmn.2006.03.0002

[Rankin 2013] Rankin, J., Enhancing Fatigue Lifetimes and Precision Component Shaping by Laser Peening. Metal Improvement Company, 2013, pdf. October 14 2019. Available from < https://jteg.ncms.org/wpcontent/gallery/Briefings/Laser-Peening-FRCSW.pdf >

[Gujba 2014] Gujba, A.K., Medraj, M., et al. Laser Peening Process and Its Impact on Materials Properties in Comparison with Shot Peening and Ultrasonic Impact Peening. Materials (Basel), 2014, Vol.7, No.12, pp 7925-7974, 10.3390/ma7127925

[Hfaiedh 2015] Hfaiedh, N., Peyre, P., et al. Finite element analysis of laser shock peening of 2050-T8 aluminum alloy. International Journal of Fatigue, 2015, Vol.70, pp 480-489, 10.1016/j.ijfatigue.2014.05.015

[Yoshihiro 2012] Yoshihiro, S., Yuji, S., et al. Fatigue Life Enhancement of Fillet and Butt Welded Joints after Laser Peening. Transactions of JWRI, 2012, Vol.41, No.1, 11094/23163

[Ye 2014] Ye, Ch., Suslov, S., et al. Cryogenic ultrahigh strain rate deformation induced hybrid nanotwinned microstructure for high strength and high ductility. Journal of Applied Physics, 2014, Vol.115, No.21, 10.1063/1.4881555

[Thareja 2007] Thareja, R.K., Shukla, S., et al. Synthesis and characterization of zinc oxide nanoparticles by laser ablation of zinc in liquid. Applied Surface Science, 2007, Vol.253, No.22, pp 8889-8895, 10.1016/j.apsusc.2007.04.088

[Bugayeva 2006] Bugayeva, A.A., Gupta, M.C., et al. Laser processing of inconel 600 and surface structure. Surface \& Coatings Technology, 2010, Vol.204, No.2, pp 102-111, 10.1016/j.optlaseng.2005.04.014

[Zhang 2010] Zhang, Y., You, J., et al. Effects of laser shock processing on stress corrosion cracking susceptibility of AZ31B magnesium alloy. Surface 
and Coatings Technology, August 2010, Vol.204, No.24, 10.1016/j.surfcoat.2010.03.015

[Fu 2014] Fu, J., Zhu, Y., et al. Effect of laser shock peening on mechanical properties of Zr-based bulk metallic glass. Applied Surface Science, 2014, Vol.313, pp 692-697, 10.1016/j.surfcoat.2010.03.015

[Fabbro 1990] Fabbro, R., Fournier, J., et al. Physical study of laser produced plasma in confined geometry.
Journal of Applied Physics, 1990, Vol.68, No.2, pp 775 - 784, 10.1063/1.346783

[Holroyd 2016] Holroyd, N.J.H., Scamans, G.M., Environmental Degradation of Marine Aluminum Alloys-Past, Present, and Future. CORROSION, February 2016, Vol.72, No.2, pp 136 - 143, doi.org/10.5006/1927

\section{CONTACTS:}

Ing. Jan Kaufman

HiLASE, Institute of Physics of the Czech Academy of Sciences, v.v.i.

Za Radnici, Dolni Brezany, 252 41, Czech Republic

+420 732779 225, jan.kaufman@hilase.cz 